\title{
Anxiogenic effects of $\beta$-CCE as measured in two different conditioning paradigms
}

\author{
AKIRA TSUDA, YOSHISHIGE IDA, HIROSHI NISHIMURA, and MASATOSHI TANAKA \\ Kurume University School of Medicine, Kurume, Japan
}

\begin{abstract}
The behavioral effects of the benzodiazepine-receptor inverse agonist ethyl- $\beta$-carboline-3carboxylate ( $\beta$-CCE) were evaluated in male Wistar rats using two different conditioning paradigms sensitive to aversively motivated responses. In the conditioned defensive burying (CDB) paradigm, rats were given a shock with a wire-wrapped prod mounted on one end-wall of a test chamber with bedding material on the floor. The time engaged in CDB (i.e., pushing and spraying the bedding material toward the prod with rapid movements of the forepaws) was subsequently measured. Acute administration of $\beta$-CCE $(0.1,0.5,1.0$, or $5.0 \mathrm{mg} / \mathrm{kg})$ for shocked rats significantly increased the duration of postshock CDB in a dose-dependent fashion, as compared with vehicle-treated rats. However, $\beta$-CCE by itself did not affect the occurrence of spontaneous burying for control rats that were not exposed to the conditioning shock. In the place-conditioning paradigm, rats were given $\beta$-CCE $(0.1,0.5,1.0$, or $5.0 \mathrm{mg} / \mathrm{kg})$ in association with one set of salient external-chamber stimuli and a vehicle was administered in association with a different set of stimuli on 3 alternate days. The time spent on each side of the two end-compartments was then measured. Treatment with $5.0 \mathrm{mg} / \mathrm{kg} \beta$-CCE, but not with the other doses, resulted in a significant conditioned place aversion for the drug-associated side, as compared with the vehicle-treated rats. These results provide further support for the hypothesis that $\beta$-CCE potentiates conditioned behavioral effects characterized as "fear" or "anxiety."
\end{abstract}

Recent evidence has shown that benzodiazepinereceptor inverse agonists, including ethyl- $\beta$-carboline3-carboxylate $(\beta$-CCE), methyl- $\beta$-carboline-3-carboxylate $(\beta$-CCM), and $\mathrm{N}$-methyl- $\beta$-carboline-3-carboxamide (FG7142 ), produce behavioral and physiological effects that are similar to those observed during stressful or anxietyrelated conditions (see Braestrup \& Nielsen, 1986; Pellow \& File, 1984, for reviews). Administration of $\beta$-CCE or $\beta$-CCM to rats caused a reduction in social interaction (File, Lister, \& Nutt, 1982) and exploratory activity in an elevated plus-maze (Pellow \& File, 1986), and facilitated preference for a dark chamber in mice (Belzung, Misslin, Vogel, Dodd, \& Chapouthier, 1987). These findings reflect the rodent's natural fearful (or anxious) tendency to avoid bright and unfamiliar surroundings. Other studies have found that several $\beta$-carboline derivatives activated the cardiovascular system in primates (Crawley et al., 1985), the hypothalamic-pituitary-adrenocortical axis in rats (Pellow \& File, 1985), and the mesofrontal dopaminergic system in rats (Claustre, Rivy, Dennis, \& Scatton, 1986; Tam \& Roth, 1985) in a manner similar to that produced by aversive events.

This study was supported by grants from the Ministry of Education, Science, and Culture of Japan (A. Tsuda), the Pharmacopsychiatry Research Foundation (Y. Ida), and the Japan Foundation for Health Sciences (M. Tanaka). We are grateful to Gary B. Glavin of the Department of Pharmacology and Therapeutics, University of Manitoba, Winnipeg, Manitoba, Canada for his kind reviewing of an earlier version of this manuscript. Address reprint requests to Akira Tsuda, Department of Pharmacology, Kurume University School of Medicine, Kurume 830, Japan.
Although the reports cited above suggest that several $\beta$-carboline compounds have anxiogenic properties in natural, or unconditioned, behavioral and physiological reactions, only a few studies have investigated the anxiogenic actions of these compounds under learning paradigms that employ aversive stimuli. Some investigators have found that in a conflict situation with food or water reinforcement, $\beta$-CCM and FG-1742 caused a significant suppression in punished appetitive responding in mice and rats, which were described as proconflict effects (Corda, Blaker, Mendelson, Guidotti, \& Costa, 1983; Prado de Carvalho, Grecksch, Chapouthier, \& Rossier, 1983). These conflict paradigms, however, have included some possible confounding factors that make the interpretation of anxiogenic drug effects difficult, as measured by ongoing responding. For example, an animal's responding on punished schedules is modulated by these drugs' sedative and anorectic actions (Pellow \& File, 1984) as well as by their anxiogenic action.

In order to gain a better understanding of the anxiogenic effects of benzodiazepine-receptor inverse agonists, it is worthwhile to investigate the effects of $\beta$-carbolines on aversively motivated learned (or conditioned) behavior in experiments that do not have some of the shortcomings mentioned above. In the present study, therefore, we investigated the anxiogenic behavioral effects of $\beta-C C E$ in two different conditioning paradigms: (1) a conditioned defensive burying (CDB) paradigm and (2) a place-conditioning paradigm. Previous studies have suggested that the CDB paradigm is a useful and simple method for the preclinical evaluation 
of anxiolytic and anxiogenic drugs (Treit, Pinel, \& Fibiger, 1981; Tsuda et al., 1987). In this paradigm, rats were given a shock with a wire-wrapped prod mounted on one end-wall of a test chamber with bedding material on the floor, and the time the rats subsequently spent spraying the bedding material toward the shock prod was measured. It was expected that $\beta$-CCE would potentiate $\mathrm{CDB}$ if this compound produces behavioral effects characterized as anxiety or fear.

The other conditioning paradigm that we used in the present experiment was place conditioning. In this paradigm, drug experience was combined with a salient environmental stimulus; the subsequent avoidance of this environment was used as a measure of the aversive nature of the drug (Amalric, Cline, Martinez, Bloom, \& Koob, 1987; Mucha, van der Kooy, O'Shaughnessy, \& Bucenieks, 1982). It was expected that if $\beta$-CCE has anxiety-related interoceptive-discriminative cue properties, this compound would produce place aversion for the drug-associated environment when rats were given a postconditioning preference test.

\section{METHOD}

\section{Subjects}

One hundred twenty male Wistar rats, each weighing 230-270 g, were used as subjects. The animals were housed in groups of 3-4 per cage and kept under a normal 12:12 light:dark cycle, with ad lib food and water, in an air-conditioned room $\left(24^{\circ} \pm 1^{\circ} \mathrm{C} ; 50 \% \pm 10 \%\right.$ r.h.).

\section{Apparatus}

For the CDB paradigm, a transparent rectangular acrylic plastic box $(45 \times 30.5 \times 44 \mathrm{~cm})$ was used as the testing chamber. The floor of the chamber consisted of $5 \mathrm{~cm}$ of white-flake bedding material (Charles River Japan, Inc., Atsugi, Kanagawa). A black carbonate prod $(6.5 \mathrm{~cm}$ long $\times 1.2 \mathrm{~cm}$ diameter $)$, which was wrapped with two uninsulated wires, was mounted in the center of an end wall of the testing chamber, $2 \mathrm{~cm}$ above the bedding material. An aversive stimulus generated by a shock generatorscrambler (SGS-001, Muromachi Kikai Co., LTD, Tokyo) was delivered to the wires of the shock prod.

For the place-conditioning paradigm, a rectangular box with three compartments, separated by guillotine doors, was used as the testing chamber. The two end-compartments measured $18 \times 18 \times$ $20 \mathrm{~cm}$; the middle compartment measured $10.5 \times 18 \times 20 \mathrm{~cm}$. One end-compartment had white acrylic walls and a stainless-steel grid floor. The other end-compartment had black wooden walls, and the floor of the compartment consisted of $3 \mathrm{~cm}$ of white-flake bedding material. The middle room had brown plywood walls and floor.

\section{Procedure}

Drugs. $\beta$-CCE (Research Biochemicals, Inc., Wayland, MA) was suspended by ultrasonic dispersion in distilled water with a drop of Tween 80 per $3.5 \mathrm{ml}$. The doses used were $0.1,0.5,1.0$, and $5.0 \mathrm{mg} / \mathrm{kg}$ body weight in both the CDB and the place-conditioning paradigms; these dosages were selected based upon research using the drug in other aversive situations (Corda et al., 1983; Crawley et al., 1985; File et al., 1982). All injections were made intraperitoneally (i.p.) immediately before conditioning at a volume of $2.0 \mathrm{ml} / \mathrm{kg}$.
CDB paradigm. The subjects were exposed to the test chamber for one 30-min habituation session on each of 4 consecutive days. On Day 5, the rats were assigned ( $n=8$ per group) to an injection condition (vehicle, $0.1,0.5,1.0$, or $5.0 \mathrm{mg} / \mathrm{kg} \beta$-CCE), on the basis of the number of contacts with the shock prod in the habituation periods, to balance the tendency for neophobia of the shock prod. Immediately after injection, the rats were placed individually into the chamber. When half of the rats (shocked condition) first touched the shock prod with their forepaws, the experimenter initiated the shock ( $4 \mathrm{~mA})$, which was terminated when the paw was withdrawn from the shock prod. The rat then spent the remainder of the session confined to the chamber for a 15-min postshock burying test period. The remaining rats (nonshocked condition) were placed into the chamber for the same period of time, but received no shock when they touched the shock prod. During the test session, CDBrelated responses were observed by two independent observers, who were unaware of the animals' individual treatment, using standard timers and event counters. The CDB-related responses included the number of contacts with the shock prod, latency to initiate the first CDB, frequency and amount of time spent in CDB, height of the piles of bedding, and number of approach-avoidance responses. The CDB behavior was defined as a series of stereotyped sequences of the rat moving toward the shock prod and pushing and spraying a pile of bedding material toward the prod with rapid movements of the snout and forepaws (Pinel \& Treit, 1978). The approachavoidance behavior was defined by a rat oriented toward the shock prod in an extended position, and suddenly withdrawing from it. These measures have high interobserver reliability ranging from $r=0.86$ ( $p<.01$, duration of burying) to $r=0.98(p<.01$, number of contacts with the shock prod).

Place-conditioning paradigm. The place-conditioning paradigm consisted of a preconditioning, a conditioning, and a postconditioning (test) phase. On Day 1 (preconditioning phase), the rat was initially placed in the brown compartment and could choose between the black and the white compartments that would later be used for conditioning. The total duration spent in each compartment and the number of entries into the black and white compartments were manually recorded during the 10 -min preconditioning phase by two independent observers who were unaware of the animals' individual treatment. The interobserver reliability of these measures was established by the product-moment correlation between the two sets of scores (time spent, $r=0.99, p<.01$; number of entries, $r=$ $0.99, p<.01)$. For the conditioning phase, each rat $(n=8$ per group) in five different groups (vehicle, $0.1,0.5,1.0$, or $5.0 \mathrm{mg} / \mathrm{kg}$ $\beta$-CCE) was conditioned for $30 \mathrm{~min}$ each day for 6 consecutive days. The rats were placed in the appropriate compartment immediately after injection, alternating between vehicle and $\beta$-CCE injections on each consecutive day. Assignment of the drug dose with the environment for each rat was performed by counterbalancing the drugassociated location without regard to each rat's initial preference. The first day of conditioning for rats in the drug groups was counterbalanced between drug pairing and vehicle pairing to control for any interaction between the last drug administration and the testing day (Amalric et al., 1987). Rats in the vehicle groups were given a vehicle injection, irrespective of the conditioned compartment. The procedure used in the postconditioning (test) phase was exactly the same as that used for the preconditioning phase, with the observers blind to previous pairing conditions. Place aversion (or preference) for the conditioned side was established by comparing the time spent (in seconds) in the compartment during preconditioning with the time spent during postconditioning. Difference scores were obtained for each rat by subtracting the time spent (in seconds) in the compartment paired with the drug during preconditioning from the time spent during postconditioning.

Statistics. Data were analyzed by analysis of variance (ANOVA) followed by post hoc Tukey's hsd tests. 


\section{RESULTS}

Data from the CDB paradigm are presented in Table 1 . The administration of $\beta$-CCE by itself did not produce spontaneous burying for nonshocked control rats. For shocked rats, however, $\beta$-CCE caused dose-dependent significant increases in duration [condition, $F(1,69)=$ $87.7, p<.01$; dose, $F(4,69)=3.8, p<.01$; condition $\times$ dose, $F(4,69)=3.5, p<.05]$ and frequency of CDB [condition, $F(1,69)=108.2, p<.01 ;$ dose, $F(4,69)=$ $2.7, p<.05$; condition $\times$ dose, $F(4,69)=3.2$, $p<.05$ ]. The drug also caused significant changes in the number of approach-avoidance responses [condition, $F(1,69)=46.7, p<.01 ;$ dose, $F(4,69)=4.6, p<.01]$ and in height of pile [condition, $F(1,69)=125.1$, $p<.01$; dose, $F(4,69)=3.0, p<.05$; condition $\times$ dose, $F(4,69)=3.0, p<.05$ ], as well as a significant decrease in the number of contacts with the shock prod [condition, $F(1,69)=137.2, p<.01$; dose, $F(4,69)=$ $8.4, p<.01$; condition $\times$ dose, $F(4,69)=7.1$, $p<.01]$. In addition, the latency of the first CDB in shocked rats was significantly reduced [condition, $F(1,69)$ $=137.2, p<.01]$, but this was unrelated to $\beta-\mathrm{CCE}$ administration. There was no significant difference in terms of the latency of touches of the shock prod during conditioning. This confirms the fact that we matched treatment groups on this variable.

Data from the place-conditioning paradigm are shown in Figure 1. An initial preference for the black compartment over the white one was observed among treatment groups, but this difference did not reach statistical significance. ANOVAs of the data of time spent in each compartment revealed a significant main effect for the conditioning factor in the conditioned side $[F(1,66)=5.6$, $p<.05]$ and a significant interaction of conditioning $\times$ group in the nonconditioned side $[F(4,66)=2.9$, $p<.05]$, as well as a significant main effect for the conditioning $[F(1,66)=8.6, p<.05]$ and a significant interaction of conditioning and group in the choice side $[F(4,66)=3.8, p<.05]$. There was no significant main effect for group in either side. Although the conditioning $X$ group interaction did not reach statistical significance on the conditioning side, post hoc Tukey's hsd comparisons $(\alpha<.05)$ were conducted in cases in which a prior prediction had been made. These comparisons indicated that the rats injected with $5.0 \mathrm{mg} / \mathrm{kg} \beta$-CCE during the conditioning phase, but not those injected with the other doses, later displayed a place aversion for the compartment that was paired with $\beta$-CCE in the conditioning phase, even though they were in a drug-free state. The rats injected with $5.0 \mathrm{mg} / \mathrm{kg} \beta$-CCE also showed a significant preference for the compartment that was paired with the vehicle in the conditioning phase, as compared with the control animals.

\section{DISCUSSION}

The results of the present study show that anxiogenic effects of $\beta$-CCE, the prototype benzodiazepine-receptor inverse agonist, were detected in two different types of learning paradigms. These paradigms were different from several other behavioral tests, including social interaction (File et al., 1982), light-dark choice (Belzung et al., 1987), forced-swim (Nishimura, Ida, Tsuda, \& Tanaka, in press), stress-induced ultrasounds (Gardner \& Budhram, 1987), and the conflict test (Prado de Carvalho et al., 1983), which previously revealed the behavioral anxiogenic actions of several $\beta$-carboline compounds.

Table 1

Summary of Conditioned Defensive Burying-Related Responses

\begin{tabular}{|c|c|c|c|c|c|c|c|c|c|c|}
\hline & \multicolumn{2}{|c|}{ Vehicle } & \multicolumn{2}{|c|}{$\beta-\mathrm{CCE} 0.1 \mathrm{mg} / \mathrm{kg}$} & \multicolumn{2}{|c|}{$\beta$-CCE $0.5 \mathrm{mg} / \mathrm{kg}$} & \multicolumn{2}{|c|}{$\beta-\mathrm{CCE} 1.0 \mathrm{mg} / \mathrm{kg}$} & \multicolumn{2}{|c|}{$\beta-\mathrm{CCE} 5.0 \mathrm{mg} / \mathrm{kg}$} \\
\hline & $M$ & $S E M$ & $M$ & $S E M$ & $M$ & SEM & $M$ & SEM & $M$ & $S E M$ \\
\hline \multicolumn{11}{|c|}{ Nonshock Condition } \\
\hline Duration of burying (sec) & 3.63 & 2.4 & 5.88 & 4.0 & 0.75 & 0.6 & 9.63 & 6.3 & 0.25 & 0.3 \\
\hline No. of burying responses & 2.13 & 1.2 & 1.88 & 1.0 & 0.38 & 0.3 & 2.38 & 1.7 & 0.25 & 0.3 \\
\hline Latency of burying & 618.75 & 137.4 & 629.13 & 132.9 & 758.13 & 98.1 & 749.38 & 100.5 & 793.13 & 106.9 \\
\hline No. of approach/avoidance responses & 0.00 & 0.0 & 0.88 & 0.5 & 0.00 & 0.0 & 0.00 & 0.0 & 0.00 & 0.0 \\
\hline Height of pile $(\mathrm{cm})$ & 0.00 & 0.0 & 0.00 & 0.0 & 0.00 & 0 & 0.00 & 0.0 & 0.00 & 0.0 \\
\hline No. of contacts with shock prod & 8.34 & 1.5 & 6.38 & 0.7 & 12.50 & 1.2 & 8.25 & 1.4 & 3.38 & $0.9 *$ \\
\hline Latency of first contact (sec) & 28.25 & 13.9 & 19.23 & 10.4 & 16.38 & 8.1 & 35.38 & 13.3 & 42.88 & 16.8 \\
\hline \multicolumn{11}{|c|}{ Shock Condition } \\
\hline Duration 0 & 58.78 & $18.68 \dagger$ & 78.29 & $41.7 \dagger$ & 186.4 & $39.2 \ddagger$ & 194.11 & $22.1 \ddagger$ & 102.29 & $28.2 \ddagger$ \\
\hline No. of burying responses & 16.22 & $3.6 \dagger$ & 11.86 & $5.3 \dagger$ & 33.00 & $6.3 \ddagger$ & 34.33 & $2.8 \ddagger$ & 27.86 & $7.7 \ddagger$ \\
\hline Latency of burying (sec) & 374.33 & $127.0 \dagger$ & 360.71 & $73.0 \dagger$ & 365.00 & $112.4 \dagger$ & 272.11 & $93.1 \dagger$ & 286.00 & $159.4 \dagger$ \\
\hline No. of approach/avoidance responses & 2.44 & $0.5 \dagger$ & 4.86 & $1.4 \ddagger$ & 1.86 & $0.6 \dagger$ & 1.44 & $0.5 \dagger$ & 2.43 & $0.8 \dagger$ \\
\hline Height of pile $(\mathrm{cm})$ & 2.61 & $0.8 \dagger$ & 2.50 & 1.0 & 6.14 & & 6.11 & $0.45 \ddagger$ & 2.90 & $0.9 \dagger$ \\
\hline No. of contacts with shock prod & 1.67 & $0.2 \dagger$ & 1.86 & $0.3 \dagger$ & 1.71 & & 1.00 & $0.0 \ddagger$ & 1.14 & $0.1 \ddagger$ \\
\hline Latency of first contact (sec) & 14.11 & 3.3 & 48.86 & 18.1 & 26.43 & 7.6 & 55.33 & 16.8 & 26.43 & $7.0^{\circ}$ \\
\hline
\end{tabular}

*Versus respective vehicle $(\alpha<.05)$. $\ddagger$ Versus respective nonshock condition $(\alpha<.05) . \quad \ddagger V e r s u s$ respective vehicle and versus respective nonshock condition (both $\alpha \mathrm{s}<.05$ ). 

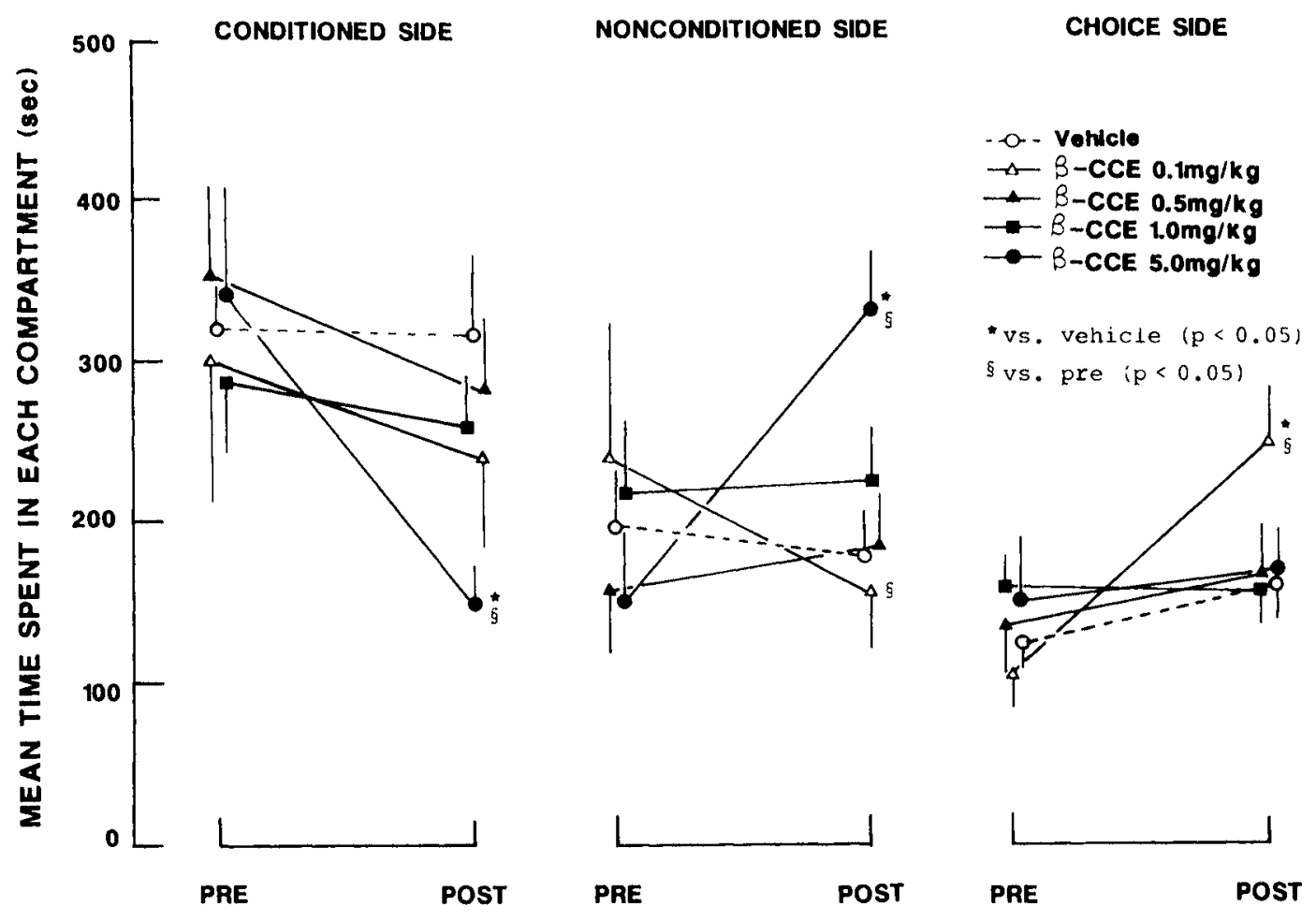

\section{CONDITIONING}

Figure 1. Mean ( \pm SEM) time (in seconds) spent in the conditioned (drug-associated) side, the nonconditioned (vehicleassociated) side, and the choice side in the preconditioning and postconditioning (test) phases.

In the CDB paradigm, $\beta$-CCE administered at $0.5,1.0$, and $5.0 \mathrm{mg} / \mathrm{kg}$, but not at $0.1 \mathrm{mg} / \mathrm{kg}$, further potentiated shock-induced CDB, in rats that had been exposed to the conditioning shock, as compared with vehicle-treated rats. This drug-induced enhancement of CDB, which is indicative of an anxiogenic action, was followed by initial periods of freezing, as shown by the disappearance of approach-avoidance responses and a relatively reduced latency to bury. On the other hand, pretreatment with $\beta$-CCE by itself did not result in any changes in CDBrelated responses for control rats which had not undergone fear conditioning. Moderate doses $(0.5$ and $1.0 \mathrm{mg} / \mathrm{kg})$ of $\beta$-CCE facilitated postshock CDB more than did lower $(0.1 \mathrm{mg} / \mathrm{kg})$ or higher $(5.0 \mathrm{mg} / \mathrm{kg})$ doses. The $5-\mathrm{mg} / \mathrm{kg}$ dose of $\beta$-CCE was probably too high to elicit $\mathrm{CDB}$, since the probability of CDB is greater at moderate levels of fear (Tsuda, Ida, \& Tanaka, 1988a). This finding is in agreement with previous studies in which $\beta$-CCE was found to be aversive in doses from $200 \mu \mathrm{g} / \mathrm{kg}$ administered intravenously (i.v.) to $2 \mathrm{mg} / \mathrm{kg}$ i.p., whereas a dose below $0.1 \mathrm{mg} / \mathrm{kg}$ i.v. or $0.5 \mathrm{mg} / \mathrm{kg}$ i.p. and a dose above $5 \mathrm{mg} / \mathrm{kg}$ i.p. were not aversive (Crawley et al., 1985; Corda et al., 1983; Nishimura et al., in press).

To our knowledge, this is the first report that indicates that a benzodiazepine-receptor inverse agonist potentiates CDB, which presumably reflects a negative motivational state such as fear or anxiety (Pinel \& Treit, 1978; Tsuda et al., 1988). Treit (1987) recently failed to demonstrate anxiogenic effects of $\gamma$-amino-butyric acid (GABA)/ benzodiazepine-receptor complex agents, such as picrotoxin, pentylenetetrazol, Ro $15-1788$, or CGS 8216 . The results of the present study support our previous finding that the CDB paradigm is sufficiently sensitive to identify both anxiolytic (diazepam) and anxiogenic (yohimbine) drug profiles (Tsuda, Ida, \& Tanaka, 1988b). The present results also extend the observation that this paradigm is useful for screening anxiety-related drugs in rats, considering the simplicity and reliability of this particular form of aversive learning (Treit et al., 1981).

The anxiogenic action of $\beta$-CCE was shown in the place-conditioning paradigm that we used as another test in this study. However, our results in this paradigm failed to fulfill the pharmacological criteria of dose-dependent sensitivity. The place-conditioning paradigm is a Pavlovian-operant interaction-conditioning model of druginduced anxiety for the study of drug reinforcement (Amarlic et al., 1987; Mucha et al., 1982). The perception of the drug's action by the animal is associated with salient environmental stimuli, and the subsequent preference or avoidance of this environment is then motivated depending on the nature of the drug-induced subjective cue. Hence, we hypothesize that the avoidance displayed by $\beta$-CCE-treated rats for the drug-paired compartment reflects a conditioned aversion, which is caused by drug- 
induced fear or anxiety (the interoceptive discriminative stimulus).

The present data using the place-conditioning paradigm demonstrate that the administration of $\beta$-CCE at $5.0 \mathrm{mg} / \mathrm{kg}$, but not at $0.1,0.5$, or $1.0 \mathrm{mg} / \mathrm{kg}$, resulted in conditioned place aversion. Administration of $\beta$-CCE at $5.0 \mathrm{mg} / \mathrm{kg}$ significantly decreased the time spent in the drug-associated compartment (conditioned side) and increased the time spent in the vehicle-associated compartment (nonconditioned side), as compared with vehicletreated rats. The other doses $(0.1,0.5$, and $1.0 \mathrm{mg} / \mathrm{kg})$ of $\beta$-CCE produced no conditioned place aversion. Only the animals given $\beta$-CCE at $5.0 \mathrm{mg} / \mathrm{kg}$ seemed highly tense and alert. Therefore, it appears that the explicit sensation derived from the drug is important in order to acquire a reinforcing conditioned response in which the reinforcing characteristics of the drug become substitutes for environmental stimuli.

It has been reported that benzodiazepines, such as diazepam and lorazepam, can produce a conditioned place preference for the drug-appropriate side (File, 1986; Spyraki, Kazandjian, \& Varonos, 1985). In contrast, the present data indicate that the benzodiazepine-receptor inverse agonist $\beta$-CCE produces a conditioned place aversion for the drug-appropriate side (i.e., it is indicative of an anxiogenic action), but this is significant only at the highest dose $(5.0 \mathrm{mg} / \mathrm{kg})$ tested. These findings are in line with a previous report that showed that the pyrazoloquinoline CGS 8216, a benzodiazepine-receptor antagonist, is only anxiogenic and aversive at higher doses in the placeconditioning model system (File, 1986).

In summary, the results of the present study show anxiogenic effects of $\beta$-CCE, as measured in two different model systems of aversive conditioning. Our results indicate that the conditioned defensive burying paradigm is more sensitive to the anxiogenic actions of $\beta$-CCE than is place conditioning. Taken together with previous physiological and biochemical findings (Claustre et al., 1986; Crawley et al., 1985), these results suggest that $\beta$ $C C E$ is able to provoke unconditioned and/or conditioned anxiety-like states in animals.

\section{REFERENCES}

Amalric, M., Cline, E. J., Martinez, J. L., Jr., Bloom, F. E., \& KoOB, G. F. (1987). Rewarding properties of $\beta$-endorphin as measured by conditioned place preference. Psychopharmacology, 91 , 14-19.

Belzung, C., Misslin, R., Vogel, E., Dodd, R. H., \& ChapouthIER, G. (1987). Anxiogenic effects of methyl- $\beta$-carboxylate in a light/dark choice situation. Pharmacology Biochemistry \& Behavior, 28, 29-33.

BraestruP, C., * NIELSEN, M. (1986). Benzodiazepine receptor binding in vivo and efficacy. In R. W. Olsen \& J. C. Venter (Eds.), Benzodiazepine/GABA receptors and chloride channel: Structural and functional properties (pp. 167-184). New York: Liss.

Claustre, Y., Rivy, J. P., Dennis, T., Scatton, B. (1986). Pharmacological studies on stress-induced increase in frontal cortical dopa- mine metabolism in the rat. Journal of Pharmacology \& Experimental Therapeutics, 238, 693-700.

Corda, M. G., Blaker, W. D., Mendelson, W. B., Guidotti, A., \& Costa, E. (1983). $\beta$-Carbolines enhance shock-induced suppression of drinking in rats. Proceedings of the National Academy of Science, 80, 2072-2076.

Crawley, J. N., Ninan, P. T., Pickar, D., Chrousos, G. P., Linnolla, M., Skolnick, P., Paul, S. M. (1985). Neuropharmacological antagonism of the $\beta$-carboline-induced "anxiety" response in rhesus monkeys. Journal of Neuroscience, 5, 477-485.

FILE, S. E. (1986). Aversive and appetitive properties of anxiogenic and anxiolytic agents. Behavioural Brain Research, 21, 189-194.

FiLe, S. E., Lister, R. G., \& NUTT, D. J. (1982). The anxiogenic action of benzodiazepine antagonists. Neuropharmacology, 21, 1033-1037.

GARDNER, C., \& Budhram, P. (1987). Effects of agents which interact with central benzodiazepine binding sites on stress-induced ultrasounds in rat pups. European Journal of Pharmacology, 134, 275-283.

Mucha, R. F., VAN der KoOY, D., O'Shaughnessy, M., \& BuCENIEKs, P. (1982). Drug reinforcement studies by the use of place conditioning in rat. Brain Research, 243, 91-105.

Nishimura, H., IDA, Y., TsudA, A., TANaKa, M. (in press). Opposite effects of diazepam and $\beta$-CCE on immobility and strawclimbing behavior of rats in a modified forced-swim test. Pharmacology, Biochemistry \& Behavior.

Pellow, S., \& FIL, S. E. (1984). Multiple sites of action for anxiogenic drugs: Behavioral, electrophysiological and biochemical correlations. Psychopharmacology, 83, 304-315.

Pellow, S., \& File, S. E. (1985). The effects of putative anxiogenic compounds (FG 7142, CGS 8216 and Ro 15-1788) on the rat corticosterone response. Physiology \& Behavior, 35, 587-590.

Pellow, S., \& File, S. E. (1986). Anxiolytic and anxiogenic drug effects on exploratory activity in an elevated plus-maze: A novel test of anxiety in the rat. Pharmacology Biochemistry \& Behavior, 24, 525-529.

Pinel, J. P. J., \& TReit, D. (1978). Burying as a defensive response in rats. Journal of Comparative \& Physiological Psychology, 92, 708-712.

Prado de Carvalho, L., Grecksch, G., Chapouthier, G., \& RosSIER, J. (1983). Anxiogenic and non-anxiogenic benzodiazepine antagonists. Nature, 301, 64-66.

Spyraki, C., Kazandjian, A., Varonos, D. (1985). Diazepaminduced place preference conditioning: Appetitive and antiaversive properties. Psychopharmacology, 87, 225-232.

TAM, S., RoTH, R. H. (1985). Selective increase in dopamine metabolism in the prefrontal cortex by the anxiogenic beta-carboline FG 7142. Biochemical Pharmacology, 9, 1595-1598.

TrerT, D. (1987). Ro 15-1788, CGS 8216, picrotoxin, and pentylenetetrazol: Do they antagonize anxiolytic drug effects through an anxiogenic action? Brain Research Bulletin, 19, 401-405.

Trert, D., Pinel, J. P. J., \& Fibiger, H. C. (1981). Conditioned defensive burying: A new paradigm for the study of anxiolytic agents. Pharmacology Biochemistry \& Behavior, 15, 619-626.

TsUDA, A., IDA, Y., \& TANAKA, M. (1988a). Behavioral field analysis in two strains of rats in a conditioned defensive burying paradigm. Animal Learning \& Behavior, 16, 354-358.

Tsuda, A., IDA, Y., \& TANAKA, M. (1988b). The contrasting effects of diazepam and yohimbine on conditioned defensive burying in rats. Psychobiology, 16, 213-217.

Tsuda, A., Satoh, M., Shirao, I., Oguch, M., Nishimura, H., * TANAKA, M. (1987). Effects of psychotropic drugs on conditioned defensive burying in mice. Japanese Joumal of Psychopharmacology, 7, 149-150.

(Manuscript received April 4, 1988; revision accepted for publication December 1, 1988.) 